\title{
Leaf traits and photosynthetic characteristics of endangered Sinopodophyllum hexandrum (Royle) Ying under different light regimes in Southeastern Tibet Plateau
}

\author{
Q.Q. GUO ${ }^{* * * *}$, H.E. LI", C. GAO*, and R. YANG*, \\ Institute for Forest Resources \& Environment of Guizhou/College of Forestry, College of Agriculture, Guizhou \\ University, 550025 Guiyang, Guizhou, China* \\ Research Institute of Tibet Plateau Ecology, Tibet Agricultural and Animal Husbandry College, 860000 Nyingchi, \\ Tibet, China**
}

\begin{abstract}
Sinopodophyllum hexandrum (Royle) Ying, a medicinal plant, has been endangered due to alpine habitat and overuse at Southeastern Tibet Plateau. This study aimed to examine the phenotypic traits and photosynthesis of $S$. hexandrum, including their relationship with main environmental factors, under low light (LL), moderate light (ML), and high light (HL) regimes. Low specific leaf mass was observed under LL, but the stomatal density and apparent quantum yield were the highest under this regime. The phenotypic traits, except for stomatal density and net photosynthetic rate, were the most notable under ML. The leaf area, stomatal density, apparent quantum yield, dark respiration, and stomatal conductance showed the smallest values under HL. Air temperature, photosynthetically active radiation, and air vapour pressure deficit significantly affected the stomatal characteristics and photosynthesis of $S$. hexandrum individuals. Our results suggested that a moderately shaded habitat could promote leaf development and the photosynthetic ability of S. hexandrum.
\end{abstract}

Additional key words: dark respiration; environmental factor; gas exchange; stomatal characteristics.

\section{Introduction}

Plants, which are immovable organisms, grow under diversified light regimes to accumulate organic carbon through photosynthesis (Nadeem et al. 2015, Campos et al. 2016). In shrub communities, herbs are often placed below shrubs for intensive shading from sun exposure in a small clearing (Ou et al. 2015). Plants under different light intensities commonly exhibit morphological or physiological changes, especially in terms of the structure and function of leaves (Rodríguez-López et al. 2014, La Rocca et al. 2015). This phenomenon is the phenotypic trait for a given habitat, and is also a long-term-induced response of plants under a specific environment. Leaf phenotype is often regarded as an important way for plants to deal with environmental heterogeneity; this phenotype also indicates ecological adaptability (Santiago and Wright 2007, Guo et al. 2016). Thus, leaf traits are being explored at present to gain insight into the adaptability of plants to environmental stress.

Several parameters of leaf traits and photosynthesis, such as leaf area and perimeter (LA and LP), fresh leaf thickness (LT), chlorophyll (Chl) content, specific leaf mass (SLM), stomatal size and density $\left(\mathrm{S}_{\mathrm{s}}\right.$ and $\left.\mathrm{S}_{\mathrm{d}}\right)$, net photosynthetic rate $\left(P_{\mathrm{N}}\right)$, and intrinsic water-use efficiency $\left(\mathrm{WUE}_{\mathrm{i}}\right)$, can be used as representative indexes to evaluate the plant adaptation for sunny to shady environments (Givnish 1988). High LA and Chl result in large carbon assimilation and SLM under certain PAR. Stomatal activity can regulate the flux of $\mathrm{CO}_{2}$ and $\mathrm{H}_{2} \mathrm{O}$ through the leaf surface. The negative correlation between $\mathrm{S}_{\mathrm{d}}$ and $\mathrm{S}_{\mathrm{s}}$ directly affects the stomatal conductance $\left(g_{\mathrm{s}}\right)$ and the maximum net photosynthetic rate $\left(P_{\text {Nmax }}\right)$ (Camargo et al. 2011). Simultaneously, the effects of leaf traits and environmental factors on plant photosynthesis are also evident under different light regimes (Chapin et al. 1987). Sinopodophyllum hexandrum (Royle) Ying, Berberidaceae, is a perennial wild herb plant at the Southeastern Tibet

\footnotetext{
Received 27 May 2018, accepted 3 October 2018.

+Corresponding author; phone:+86-18786760728, e-mail: Yr553017@163.com

Abbreviations: Chl - chlorophyll; $E$ - transpiration rate; $g_{\mathrm{s}}$ - stomatal conductance; HL - high light regime; LA - leaf area; $\mathrm{L}_{\mathrm{CP}}$ - light-compensation point; $\mathrm{L}_{\mathrm{SP}}$ - light-saturation point; LL - low light regime; LP - leaf perimeter; LT - leaf thickness; ML medium light regime; $P_{\mathrm{N}}$ - net photosynthetic rate; $R_{\mathrm{D}}$ - dark respiration rate; $\mathrm{RH}_{\text {air }}$ - air relative humidity; $\mathrm{S}_{\mathrm{d}}-$ stomatal density; $\mathrm{SLM}-$ specific leaf mass; $\mathrm{S}_{\mathrm{s}}$ - stomatal size; $\mathrm{T}_{\text {air }}$ - air temperature; $\mathrm{VPD}_{\text {air }}-$ vapour pressure deficit of air; $\mathrm{WUE}_{\mathrm{i}}-$ intrinsic water-use efficiency; $\alpha$ - apparent quantum yield.

Acknowledgements: Financial supports by National Science Foundations of China (No. 31460079), the construction project for first-class ecology discipline in Guizhou (GNYL [2017] 007), Scientific Research Foundation for Advanced Talent of Guizhou University (201623), and Major Scientific and Technological Projects of Guizhou Province, China (No. 20163022-06) are gratefully acknowledged. All the authors contributed equally to this work and had no conflict of interest.
} 
Plateau. This plant exhibits effective anticancer function (Liu et al. 2015). Its secondary metabolite is highly effective in curing malignant tumours, rheumatism, and gynecopathy (Kumari et al. 2014). Consequently, wild types of $S$. hexandrum are artificially dug randomly because $S$. hexandrum has been classified as an endangered species since 1987 and recorded in the Chinese Plant Red Book (Fu and Chin 1992). Given the low nature reproduction rate (Ma et al. 1997), genetic diversity (Xiao et al. 2006), and habitat fragmentation (Guo et al. 2012), S. hexandrum has been identified as a first-grade municipal endangered plant of Tibet in 2005 and 2009 (Lu et al. 2011). Therefore, the protection of existing resources and promotion of population recovery are current urgent tasks. $\mathrm{Ma}$ and $\mathrm{Hu}$ (1996) reported that fewer $S$. hexandrum plants grew in the open grassland with considerable under shrub shade at the Shangri-la region of China. Intense radiation can induce dark spots on the leaf surface at high altitude localities. No reference on effects of light intensity on physiological properties is available for $S$. hexandrum. Thus, the present work aimed to determine the leaf traits and photosynthetic characteristics of $S$. hexandrum under different light regimes. The present results can aid the identification of suitable methods for the recovery of wild populations of $S$. hexandrum and for guided artificial planting.

\section{Materials and methods}

Experimental site and materials: This study was conducted at the Butterfly Valley $\left(29^{\circ} 28^{\prime} 16^{\prime \prime} \mathrm{N}, 9^{\circ} 22^{\prime} 41^{\prime \prime} \mathrm{E}\right)$ at an altitude of approximately $2,996 \mathrm{~m}$. This area is located in Bujiu Town, Nyingchi County, Southeast Tibet of China. The study area is a native alpine brush at the lower part of slope, which is the typical habitat of $S$. hexandrum. The mean annual temperature is $4.72^{\circ} \mathrm{C}$, and the monthly maximum (July) and minimum (January) mean temperatures are $13.15^{\circ} \mathrm{C}$ and $-4.82^{\circ} \mathrm{C}$, respectively. The annual mean air relative humidity $\left(\mathrm{RH}_{\text {air }}\right)$ and sunshine duration are $75.3 \%$ and $1,150 \mathrm{~h}$, respectively. The mean annual rainfall is approximately $650 \mathrm{~mm}$, which is mainly concentrated from May to September. The area also experiences a severe dry season ( $\leq 80 \mathrm{~mm}$ per month) from October to April. The soil in the study area is a mountain brown with some stones, has medium fertility, and $\mathrm{pH}$ 4.2-4.5. The dominating shrub and herb species are Rosa multiflora, Berberis julianae, Cotoneaster microphyllus, Hypericum hookerianum, S. hexandrum, Anemone rivularis, Potentilla fulgens, and Pteridium aquilinum.

Twenty well-grown adult plants of $S$. hexandrum were selected as experimental objects under different light regimes. The average size and the detailed habitats are listed in Table 1. We measured the leaf traits and photosynthetic abilities of these samples. Because of the scarcity of wild $S$. hexandrum individuals, the $P_{\mathrm{N}}$-PAR response curves and diurnal variations in photosynthesis of labelled leaves were determined first during sunny days from 12 July to 15-16 July, 2015. Second, the leaf traits were measured on 17-19 July, 2015. Each index was determined thrice during the course of experiments. Results are presented as means \pm standard deviations.
Leaf traits and stomatal characteristics: LA, LP, LT, Chl, SLM, and stomatal characteristics $\left(S_{s}\right.$ and $\left.S_{d}\right)$ were measured in 20 unbroken leaves of each labelled plant. LA, LP, and LT were measured using an LA meter $(A M-300, A D C, \mathrm{UK})$ and a digital Vernier calliper (EM$K C 150$, Elecall, Shanghai, China). The Chl content was determined by the SPAD value (SPAD-502, Konica, Japan) and correlation equation $\left[\mathrm{y}=0.236 \mathrm{e}^{0.0588 \mathrm{x}}\left(r^{2}=0.85\right)\right.$, where $x$ indicates the SPAD-502 value and $y$ indicates the $\mathrm{Chl}$ content] (Uddling et al. 2007). Clear nail polish impressions (three per leaf) from the lower and upper leaf surfaces were obtained to determine the $S_{s}$ and $S_{d}$ from a sample with 20 stomata per leaf under a fluorescence microscope (Eclipse 80i, Nikon, Japan) using a magnification of 400× and 1,000×, respectively (Aasamaa and Sõber 2011). SLM was measured in accordance with the LM/LA ratio.

$\boldsymbol{P}_{\mathrm{N}}$-PAR response curves: The labelled leaves from $S$. hexandrum individuals were measured under uniform conditions $\left[20 \pm 0.5^{\circ} \mathrm{C}, 60 \pm 5 \% \mathrm{RH}\right.$, and $380 \pm 5 \mu \mathrm{mol}\left(\mathrm{CO}_{2}\right)$ $\mathrm{mol}^{-1}$ ] between 9:30 and 11:00 h. Responses to PAR were measured at the PAR range of $0-1,600 \mu \mathrm{mol}$ (photon) $\mathrm{m}^{-2} \mathrm{~s}^{-1}$, whilst keeping the air flow of the photosynthesis measurement system ( $\mathrm{Li}-6400, \mathrm{Li}$-Cor, Lincoln, USA) constant at $500 \mu \mathrm{mol} \mathrm{s}^{-1}$. Data were automatically recorded using $\mathrm{Li}-6400$.

Light-compensation point $\left(\mathrm{L}_{\mathrm{CP}}\right)$ and saturation point $\left(\mathrm{L}_{\mathrm{SP}}\right)$ of $S$. hexandrum were the PAR values when the values of $P_{\mathrm{N}}$ were zero and maximum value, respectively. Linear regressions of PAR and $P_{\mathrm{N}}$ over the range of $0-250$ $\mu \mathrm{mol}\left(\right.$ photon) $\mathrm{m}^{-2} \mathrm{~s}^{-1}$ were used to determine $\mathrm{L}_{\mathrm{CP}}$ and dark respiration $\left(R_{\mathrm{D}}\right)$. $\mathrm{L}_{\mathrm{CP}}$ was PAR value when photosynthetic activity balanced respiratory activity, and $R_{\mathrm{D}}$ was the $P_{\mathrm{N}}$ value when PAR was zero. Apparent quantum yield $(\alpha)$ was calculated as the slope of regression line. These curves were fitted using the following nonrectangular hyperbolic equation (Thornley 1976):

$P_{\mathrm{N}}=\frac{\alpha \mathrm{PAR}+P_{\mathrm{N} \max }-\sqrt{\left(\alpha \mathrm{PAR}+P_{\mathrm{N} \max }\right)^{2}-4 \alpha \mathrm{PAR} P_{\mathrm{N} \max }}}{2 k}-R_{D}$

where $k$ is the convexity factor (Farquhar and Sharkey 1982). Maximum net photosynthetic rate $\left(P_{\mathrm{N} \max }\right)$ and $\mathrm{L}_{\mathrm{SP}}$ were estimated.

Diurnal variation of gas exchange: The diurnal variation in photosynthesis of $S$. hexandrum plants was measured under natural $\mathrm{T}_{\text {air }}$ and $\mathrm{CO}_{2}$ concentrations with an open gas-exchange system ( $\mathrm{Li}$-6400, Li-Cor, Lincoln, USA) that was operated at a flow rate of $500 \mu \mathrm{mol} \mathrm{s} \mathrm{s}^{-1}$. The instrument automatically records photosynthetic and main environmental factor parameters. We carried out the measurements once in every hour from 8:00 to 20:00 h in accordance with the procedure proposed by Tomlinson (1990).

Gas-exchange parameters were measured in three fully expanded well-grown functional leaves from three different plants $(n=3)$ under each light regime, and each measurement were repeated thrice. 
Table 1. Mean sizes and detailed habitats of 20 adult $S$. hexandrum plants. Each value denotes the mean $( \pm$ SD) of samples $[n=8,7,5$ for low (LL), medium (ML), and high light (HL), respectively] under the same light regime.

\begin{tabular}{|c|c|c|c|c|c|}
\hline Light regime & No. of plants & Height $[\mathrm{cm}]$ & Crown diameter $[\mathrm{cm}]$ & Leaf number per plant & Detailed habitats \\
\hline LL & 8 & $56.32 \pm 8.32$ & $47.56 \pm 5.32$ & $2.67 \pm 0.79$ & $\begin{array}{l}\text { Close to shrubs under the shade } \\
\text { throughout the day }\end{array}$ \\
\hline ML & 7 & $67.21 \pm 9.16$ & $65.42 \pm 4.87$ & $3.13 \pm 1.02$ & $\begin{array}{l}\text { Nearby shrubs under the shade for } \\
\text { about half a day }\end{array}$ \\
\hline HL & 5 & $53.75 \pm 8.42$ & & & Open places with no shade \\
\hline
\end{tabular}

Environmental data and statistical analyses: During the diurnal course, all the relative environmental data were recorded in each step by using $L i-6400$, including vapour pressure deficit of air $\left(\mathrm{VPD}_{\text {air }}\right)$. The ecological suitability of $S$. hexandrum was assessed using one-way analysis of variance (ANOVA). Means were compared using the Duncan's test under three light regimes. Pearson's correlation was used to assess the relationship between parameters. Statistical analyses and figure plotting were performed using SPSS 18.0 (SPSS Inc., Chicago, USA) and Sigmaplot 11.0 (Systat Software, Inc.), respectively.

\section{Results}

Morpho-anatomical leaf traits: LA and LP showed the same change trend under three light regimes, which were ranked in the following order: moderate light (ML) $>$ low light (LL) $>$ high light (HL) (Table 2). SLM, LT, and $\mathrm{Chl}$ also showed higher values for ML than those for HL and LL, which also showed significant differences. Stomata were observed only on the lower leaf surface (hypostomatous leaves). The values of $\mathrm{S}_{\mathrm{d}}$ for LL were 21.5 and $24.7 \%$ higher than those in ML and HL, respectively. The smallest $\mathrm{S}_{\mathrm{s}}$ value was observed under LL (Table 2).

$\boldsymbol{P}_{\mathrm{N}}$-PAR response curves and fitting parameters: Significant difference was observed between the photosynthetic parameters of $S$. hexandrum under the three conditions. $P_{\mathrm{N}}$ was higher under LL and HL than that under ML with the lower PAR [from $0 \mu \mathrm{mol} \mathrm{m}{ }^{-2} \mathrm{~s}^{-1}$ to approximately $240 \mu \mathrm{mol}$ (photon) $\mathrm{m}^{-2} \mathrm{~s}^{-1}$ ] (Fig. 1). However, with the increase in PAR [from 240 to 1,600 $\mu \mathrm{mol}\left(\right.$ photon) $\mathrm{m}^{-2} \mathrm{~s}^{-1}$ ], $P_{\mathrm{N}}$ under different light conditions was ranked in the following order: ML $>\mathrm{HL}>\mathrm{LL}$ (Fig. 2). The fitting parameters, such as $P_{\mathrm{N} \max }, \alpha, \mathrm{L}_{\mathrm{CP}}, \mathrm{L}_{\mathrm{SP}}$, and $R_{\mathrm{D}}$, reached the maximum values under ML (Table 3 ). The $\alpha$ under LL and ML, $P_{\mathrm{Nmax}}$ under $\mathrm{HL}$ and LL, and $\mathrm{L}_{\mathrm{SP}}$ under HL and ML showed no significant differences (Table 3).

Diurnal variation of photosynthesis parameters under natural conditions: Fluctuations in the main environmental factors (Fig. 3) and the photosynthetic parameter variation throughout the course of the day (Fig. 4) were measured. The highest $\mathrm{T}_{\text {air }}$ of approximately $23.4^{\circ} \mathrm{C}$ was observed at 14:00 h (12 July) (Fig. 3), with the highest VPD air values $(1.45 \mathrm{kPa})$ (Fig. 3). The most intense illuminations of 658 ; 1,348 ; and $1,855 \mu \mathrm{mol}$ (photon) $\mathrm{m}^{-2} \mathrm{~s}^{-1}$ were also recorded at 14:00 h for LL, ML, and HL, respectively (Fig. 3).

Diurnal variations in $P_{\mathrm{N}}$ were single-peak curves with minor fluctuations under the three light regimes. $P_{\mathrm{N}}$ under ML was higher than those under LL and HL, except that at 8:00-9:00 h. $P_{\mathrm{N}}$ under HL was higher at 8:00-11:30 and 17:30-20:00 h compared to that of LL. $P_{\mathrm{N}}$ peaks appeared at nearly 16:00, 15:00, and 11:00 h under LL, ML, and HL conditions, respectively (Fig. $4 A$ ). The $g_{\text {s }}$ values under LL and ML were also higher than that in HL. In particular, the $g_{\text {s }}$ peaks for LL and HL appeared at around 14:00 $\mathrm{h}$ and that for ML occurred at 11:00 h (Fig. 4B). The transpiration rate $(E)$ for LL was lower than those of the others during day time (Fig. 4C). During the diurnal variation, the values of $\mathrm{WUE}_{\mathrm{i}}$ for ML and HL were higher than that of LL. They kept increasing with some fluctuations from 8:00 to 16:00 $\mathrm{h}$ in three light regimes, and then reached the peak values. Therefore, they decreased from 16:00 to 20:00 h (Fig. 4D).

The correlation results between $P_{\mathrm{N}}$ and $\mathrm{WUE}_{\mathrm{i}}, \mathrm{Chl}$, $\mathrm{S}_{\mathrm{s}}, \mathrm{PAR}, \mathrm{T}_{\text {air }}$, and $\mathrm{VPD}_{\text {air }}$ in $S$. hexandrum were significant (Table 4). Nonetheless, no correlation was observed between $P_{\mathrm{N}}$ and $g_{\mathrm{s}}$, SLM, or $\mathrm{S}_{\mathrm{d}}$. A correlation was also detected between WUE $\mathrm{H}_{\mathrm{i}}$ and $g_{\mathrm{s}}, \mathrm{SLM}, \mathrm{S}_{\mathrm{d}}, \mathrm{S}_{\mathrm{s}}$, and PAR, and between SLM and Chl, $\mathrm{S}_{\mathrm{d}}, \mathrm{S}_{\mathrm{s}}$, and PAR (Table 4). Associations were also observed between $\mathrm{S}_{\mathrm{d}}$ and Chl, $\mathrm{S}_{\mathrm{s}}$, $g_{s}$, and PAR and between $\mathrm{Chl}$ and $\mathrm{S}_{\mathrm{s}}$ (Table 4). Among the

Table 2. Leaf area and perimeter (LA and LP), specific leaf mass (SLM), leaf thickness (LT), chlorophyll content (Chl), stomatal density and size $\left(\mathrm{S}_{\mathrm{d}}\right.$ and $\left.\mathrm{S}_{\mathrm{s}}\right)$ of nine $S$. hexandrum plants under three light regimes. Each value denotes the mean $( \pm \mathrm{SD})$ of three plants $(n=3)$ under the same regimes. Means within columns followed by different small letters are statistically significant at the 0.05 level.

\begin{tabular}{llllllll}
\hline $\begin{array}{l}\text { Light } \\
\text { regime }\end{array}$ & LA $\left[\mathrm{cm}^{2}\right]$ & LP $[\mathrm{mm}]$ & SLM $\left[\mathrm{mg} \mathrm{cm}^{-2}\right]$ & LT $[\mathrm{mm}]$ & Chl $\left[\mathrm{mg} \mathrm{g}^{-1}\right]$ & $\mathrm{S}_{\mathrm{d}}\left[\mathrm{mm}^{-2}\right]$ & $\mathrm{S}_{\mathrm{s}}[\mu \mathrm{m}]$ \\
\hline LL & $311.62 \pm 12.43^{\mathrm{b}}$ & $151.46 \pm 8.43^{\mathrm{b}}$ & $3.03 \pm 0.43^{\mathrm{c}}$ & $0.48 \pm 0.15^{\mathrm{c}}$ & $3.09 \pm 0.41^{\mathrm{c}}$ & $82.67 \pm 6.43^{\mathrm{a}}$ & $43.79 \pm 10.42^{\mathrm{b}}$ \\
ML & $411.87 \pm 23.01^{\mathrm{a}}$ & $201.89 \pm 10.25^{\mathrm{a}}$ & $5.61 \pm 0.31^{\mathrm{a}}$ & $0.85 \pm 0.11^{\mathrm{a}}$ & $5.27 \pm 0.45^{\mathrm{a}}$ & $64.89 \pm 8.23^{\mathrm{b}}$ & $51.93 \pm 9.42^{\mathrm{a}}$ \\
HL & $198.46 \pm 21.42^{\mathrm{c}}$ & $124.92 \pm 9.36^{\mathrm{c}}$ & $4.47 \pm 0.28^{\mathrm{b}}$ & $0.67 \pm 0.13^{\mathrm{b}}$ & $3.69 \pm 0.50^{\mathrm{b}}$ & $62.22 \pm 7.85^{\mathrm{b}}$ & $51.20 \pm 11.03^{\mathrm{a}}$ \\
$p$ & 0.001 & 0.003 & 0.000 & 0.000 & 0.001 & 0.001 & 0.000 \\
\hline
\end{tabular}



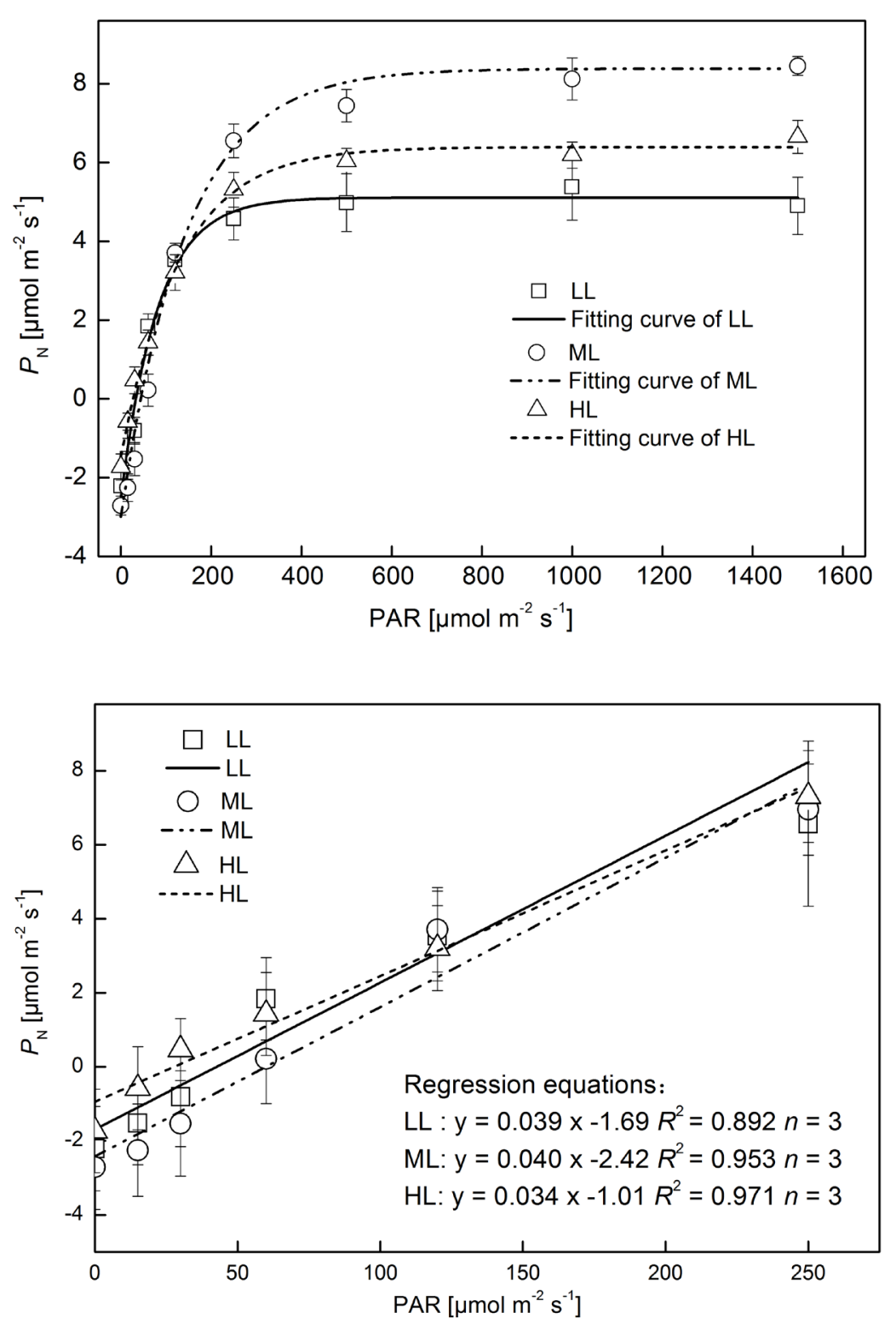

Fig. 1. Response curves of photosynthesis $\left(P_{\mathrm{N}}\right)$ photosynthetically active radiation (PAR) of $S$. hexandrum under low light (LL), medium light (ML), and high light (HL) regimes. Each value denotes the mean $( \pm \mathrm{SD})$ of three plants $(n=9)$ in the same light regimes.

Table 3. Fitting values of net photosynthetic rate $\left(P_{\mathrm{N}}\right)$-photosynthetically active radiation (PAR) curves of $S$. hexandrum plants under three light regimes. Values $( \pm \mathrm{SD})(n=9)$ within columns followed by different small letters are statistically significant at the 0.05 level.

\begin{tabular}{|c|c|c|c|c|c|}
\hline $\begin{array}{l}\text { Light } \\
\text { regime }\end{array}$ & $P_{\mathrm{N} \max }\left[\mu \mathrm{mol} \mathrm{m} \mathrm{m}^{-2} \mathrm{~s}^{-1}\right]$ & $\alpha$ & $L_{\mathrm{SP}}\left[\mu \mathrm{mol} \mathrm{m} \mathrm{m}^{-2} \mathrm{~s}^{-1}\right]$ & $L_{\mathrm{CP}}\left[\mu \mathrm{mol} \mathrm{m} \mathrm{m}^{-2} \mathrm{~s}^{-1}\right]$ & $R_{\mathrm{D}}\left[\mu \mathrm{mol} \mathrm{m}{ }^{-2} \mathrm{~s}^{-1}\right]$ \\
\hline LL & $5.36 \pm 0.23^{b}$ & $0.039 \pm 0.005^{\mathrm{a}}$ & $868.23 \pm 26.31^{b}$ & $34.51 \pm 5.43^{b}$ & $1.69 \pm 0.78^{\mathrm{b}}$ \\
\hline ML & $9.31 \pm 0.57^{\mathrm{a}}$ & $0.040 \pm 0.003^{\mathrm{a}}$ & $1030.26 \pm 28.04^{\mathrm{a}}$ & $54.87 \pm 5.92^{\mathrm{a}}$ & $2.42 \pm 0.91^{\mathrm{a}}$ \\
\hline HL & $6.38 \pm 0.61^{b}$ & $0.034 \pm 0.004^{\mathrm{b}}$ & $989.87 \pm 19.52^{\mathrm{a}}$ & $15.09 \pm 2.16^{\mathrm{c}}$ & $1.01 \pm 0.28^{\mathrm{c}}$ \\
\hline$p$ & 0.000 & 0.001 & 0.000 & 0.003 & 0.002 \\
\hline
\end{tabular}

environmental factors, the relationships of PAR, $\mathrm{T}_{\text {air, }}$, and VPD ${ }_{\text {air }}$ were significantly correlated with one another. In particular, a significant correlation was observed between PAR and $\mathrm{S}_{\mathrm{s}}$ (Table 4). Positive correlations were also observed between $P_{\mathrm{N}}$ and $\mathrm{WUE}_{\mathrm{i}}, \mathrm{Chl}, \mathrm{S}_{\mathrm{s}}, \mathrm{PAR}, \mathrm{T}_{\text {air }}$ or $\mathrm{VPD}_{\text {air }}$; between $g_{\mathrm{s}}$ and $\mathrm{S}_{\mathrm{d}}$; between WUE $\mathrm{W}_{\mathrm{i}}$ and SLM, $\mathrm{S}_{\mathrm{d}}$ or PAR; and between $\mathrm{S}_{\mathrm{s}}$ and SLM, Chl or PAR. SLM was
Fig. 2. Regression equations of photosynthesis $\left(P_{\mathrm{N}}\right)$ - photosynthetically active radiation (PAR) of $S$. hexandrum under weak light level under low light (LL), medium light (ML), and high light (HL) regimes. Each value denotes the mean $( \pm \mathrm{SD})$ of three plants $(n=9)$ in the same light regimes. correlated with $\mathrm{Chl}$ and PAR. On the contrary, a negative correlation was detected between $\mathrm{WUE}_{\mathrm{i}}$ and $\mathrm{S}_{\mathrm{s}}$. In addition, $\mathrm{S}_{\mathrm{d}}$ was associated with Chl, $\mathrm{S}_{\mathrm{s}}$ and PAR.

\section{Discussion}

Leaf traits showed significant differences with increased/ 
decreased illumination (Petter et al. 2016, Yannelli et al. 2017). For some plants, HL would result in small LA and large LT (Terashima et al. 2001, Pons 2016), and thus large SLM (Puglielli et al. 2017). On the contrary, the thin and large leaves were usually produced under LL habitats (Portsmuth and Niinemets 2007). In the meantime, Chl was also sensitive to the light conditions (Sato et al. 2015).
For example, most plants could not synthesize Chl due to the lack of the progenitor cells without sufficient light (Duanmu et al.2013). However, HL could induce plant leaves to reduce Chl synthesis (Li et al. 2014), which could be a self-protection mechanism to avoid absorbing too much light energy and photoinhibition (Tucci et al. 2010). By contrast, certain shade (ML) was beneficial to $\mathrm{Chl}$

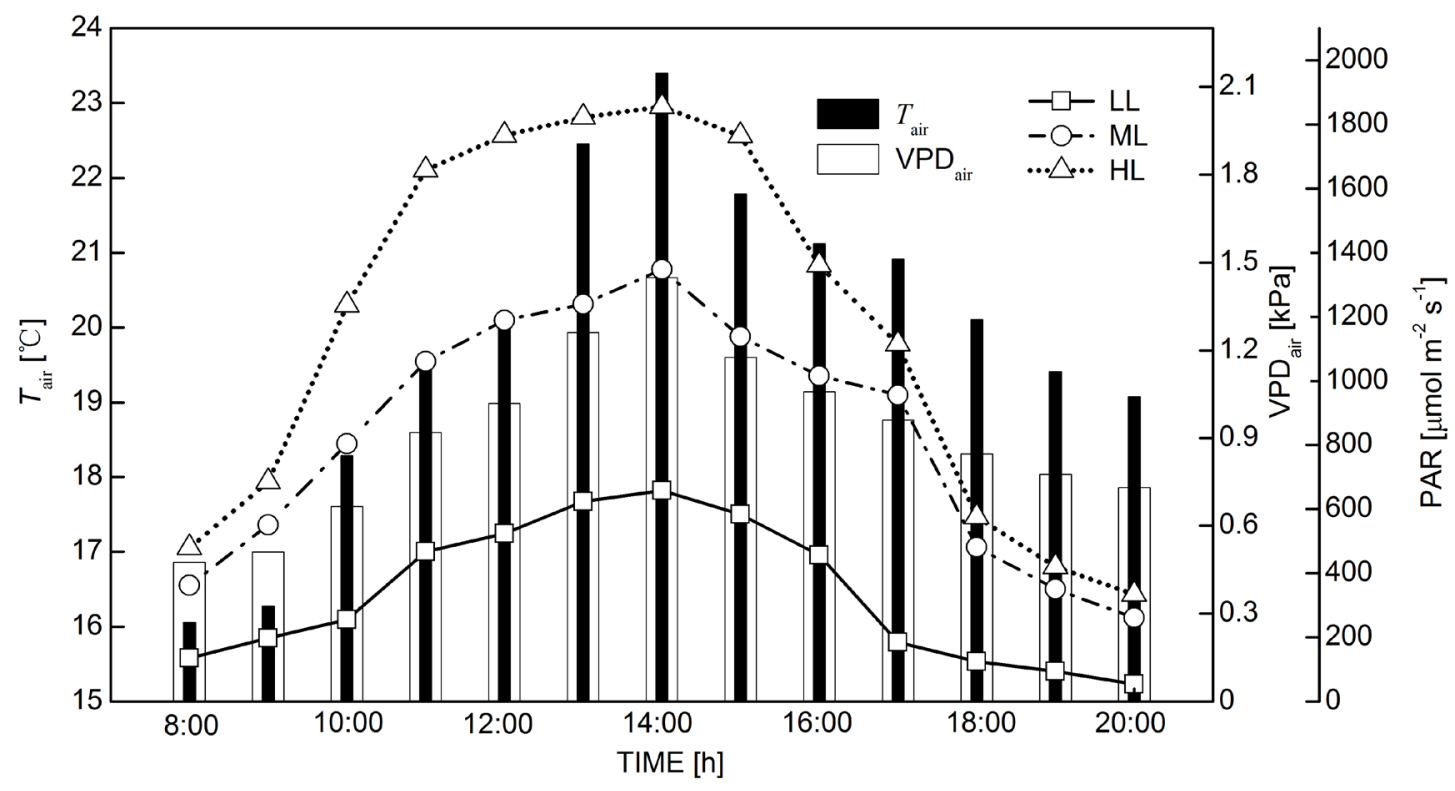

Fig. 3. Diurnal variation in air temperature $\left(\mathrm{T}_{\text {air }}\right)$, vapour pressure deficit of air $\left(\mathrm{VPD}_{\text {air }}\right)$, and photosynthetically active radiation (PAR) under low light (LL), medium light (ML), and high light (HL) regimes on 12 July 2015 (Butterfly Valley, Bujiu Town, Nyingchi County, Southeast Tibet of China).

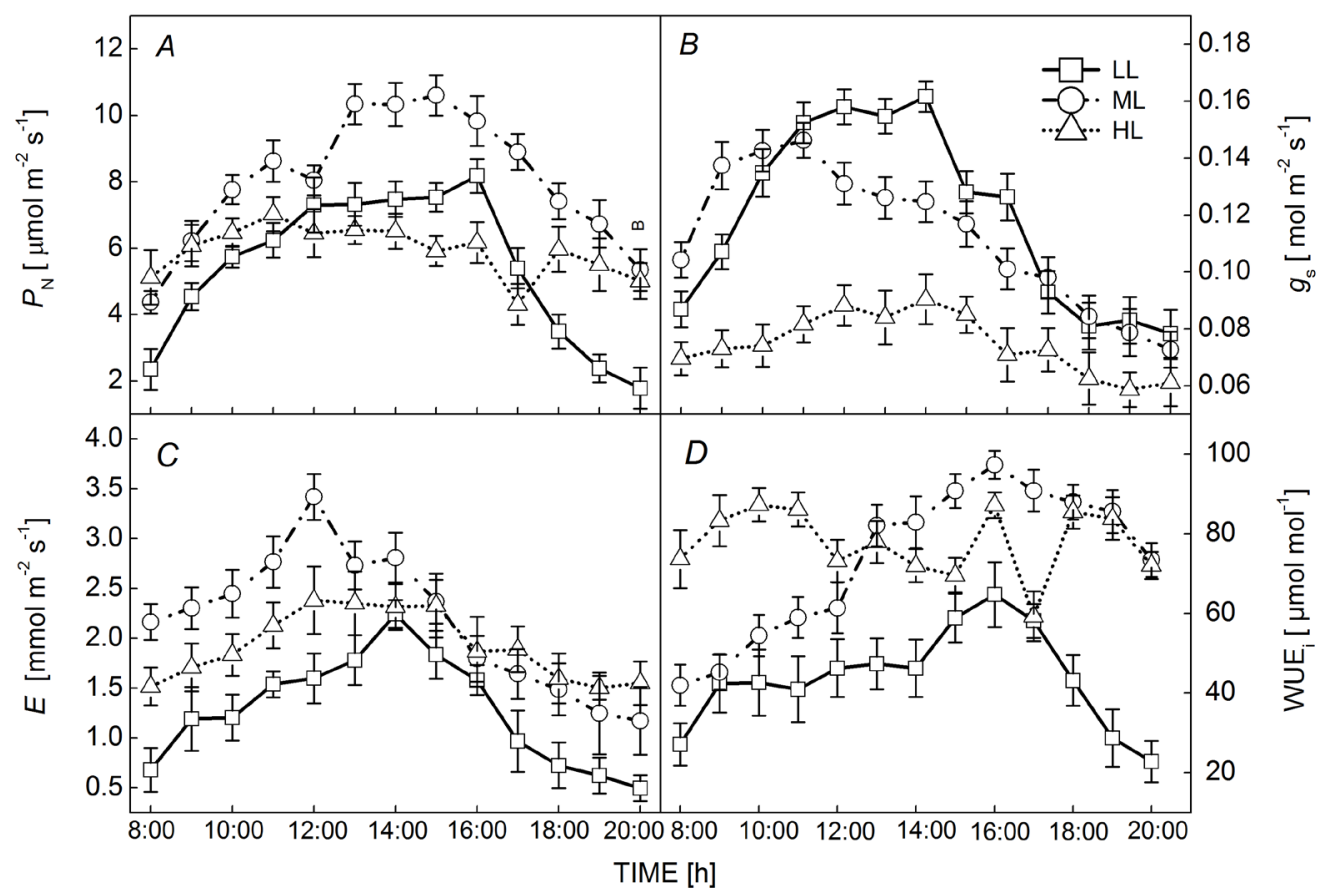

Fig. 4. Diurnal variation in net photosynthetic rate $\left(P_{\mathrm{N}}\right)(A)$, stomatal conductance $\left(g_{\mathrm{s}}\right)(B)$, transpiration rate $(E)(C)$, and intrinsic wateruse efficiency $\left(\mathrm{WUE}_{\mathrm{i}}\right)(D)$ of $S$. hexandrum under low light (LL), medium light (ML), and high light (HL) regimes. Each value denotes the mean $( \pm \mathrm{SD})$ of three plants $(n=9)$ in the same light regimes. 
Table 4. Pearson's correlation coefficients (upper right section) and $p$ values (lower left section) in terms of the leaf traits, photosynthetic parameters, and the main environmental factors. Significant differences at the 0.05 level $(n=117)$ are marked in bold.

\begin{tabular}{lllllllllll}
\hline & $P_{\mathrm{N}}$ & $g_{\mathrm{s}}$ & $\mathrm{WUE}_{\mathrm{i}}$ & $\mathrm{SLM}$ & $\mathrm{Chl}$ & $\mathrm{S}_{\mathrm{d}}$ & $\mathrm{S}_{\mathrm{s}}$ & $\mathrm{PAR}$ & $\mathrm{T}_{\text {air }}$ & VPD $_{\text {air }}$ \\
\hline$P_{\mathrm{N}}$ & - & 0.244 & $\mathbf{0 . 5 3 8}$ & 0.231 & 0.519 & -0.020 & 0.377 & 0.572 & 0.508 & 0.563 \\
$g_{\mathrm{s}}$ & 0.135 & - & $\mathbf{- 0 . 6 1 4}$ & -0.242 & 0.238 & 0.332 & -0.296 & -0.098 & 0.079 & 0.179 \\
$\mathrm{WUE}_{\mathrm{i}}$ & 0.000 & 0.000 & - & 0.583 & 0.259 & $\mathbf{- 0 . 3 9 9}$ & 0.580 & 0.530 & 0.307 & 0.264 \\
$\mathrm{SLM}$ & 0.206 & 0.137 & 0.000 & - & 0.710 & $\mathbf{- 0 . 6 6 0}$ & 0.820 & 0.591 & 0.073 & 0.094 \\
$\mathrm{Chl}$ & 0.001 & 0.144 & 0.111 & 0.000 & - & $\mathbf{- 0 . 3 7 8}$ & 0.580 & 0.283 & 0.025 & 0.071 \\
$\mathrm{~S}_{\mathrm{d}}$ & 0.905 & 0.039 & 0.012 & 0.000 & 0.018 & - & $-\mathbf{0 . 6 3 5}$ & $\mathbf{- 0 . 3 4 5}$ & 0.187 & 0.155 \\
$\mathrm{~S}_{\mathrm{s}}$ & 0.018 & 0.068 & 0.000 & 0.000 & 0.000 & 0.000 & - & 0.540 & 0.011 & 0.045 \\
$\mathrm{PAR}$ & 0.000 & 0.555 & 0.001 & 0.000 & 0.081 & 0.031 & 0.000 & - & 0.498 & 0.581 \\
$\mathrm{~T}_{\text {air }}$ & 0.001 & 0.634 & 0.057 & 0.657 & 0.881 & 0.254 & 0.945 & 0.001 & - & 0.973 \\
$\mathrm{VPD}_{\text {air }}$ & 0.000 & 0.276 & 0.105 & 0.570 & 0.666 & 0.345 & 0.788 & 0.000 & 0.000 & - \\
\hline
\end{tabular}

synthesis and area expansion; thus, the leaves with a high Chl content and SLM had large LA. Similar results had been reported in Campanulastrum americanum (Galloway et al. 2009), Syringa oblata (Xiao et al. 2015), and Olea europaea (Gregoriou et al. 2007). Our findings were consistent with these results. Therefore, the preference of $S$. hexandrum was certain shade conditions.

Stomatal characteristics were sensitive to heterogeneous light regimes in several herb species (Magyar et al. 2007). In other plant species (e.g. Taraxacum mongolicum, Arabidopsis thaliana, and S. oblata), an increase in PAR induced an increase in $\mathrm{S}_{\mathrm{d}}$ and a decrease in $\mathrm{S}_{\mathrm{s}}$ (Pigliucci et al. 2002, Zhao et al. 2007, Xiao et al. 2015). However, $S_{d}$ and $\mathrm{S}_{\mathrm{s}}$ of $S$. hexandrum leaves were reduced and increased under LL and HL habitats, respectively (Table 2). A significant negative/positive correlation was observed between PAR and $\mathrm{S}_{\mathrm{d}} / \mathrm{S}_{\mathrm{s}}$ (Table 4). Shaded samples displayed developed mechanisms, which ultimately aimed to maximise carbon gain through their ontogenetic stages towards the canopy (Kenzo et al. 2012). The strategies involved the increased stomatal density $\left(\mathrm{S}_{\mathrm{d}}\right)$ and nutrient assimilation and decreased $\mathrm{S}_{\mathrm{s}}$; small stomata responded to extreme environment that drives stomatal movements to avoid water loss (Meinzer and Grantz 1990). Our data supported the hypothesis that $\mathrm{S}_{\mathrm{d}}$ was significantly positively/ negatively correlated with $g_{\mathrm{s}}(r=0.332, p<0.05) / \mathrm{WUE}_{\mathrm{i}}$ $(r=-0.399, p<0.05)$ and significantly negatively correlated with $\mathrm{S}_{\mathrm{s}}(r=-0.635, p<0.05)$. In particular, the maximum $\mathrm{S}_{\mathrm{d}}$ and $\mathrm{S}_{\mathrm{s}}$ also appeared under ML. These results indicated that a certain shading conditions promoted the stomatal development of $S$. hexandrum. These findings were similar to those in shade-tolerant plant Trifolium repens (Huber et al. 2008). The similarity might be caused by the adaptation of phenotypic traits and acclimatisation (Pilahome et al. 2017).

The results of the $P_{\mathrm{N}}$-PAR response curves, showed that the high $\alpha$ and $R_{\mathrm{D}}$ of LL and ML suggested that certain shade promoted the light energy transformation and nutrient consumption in plant leaf, which were contrary to those under HL. Overall, lowered $\mathrm{L}_{\mathrm{CP}}[\leq 55$ $\mu$ mol(photon) $\mathrm{m}^{-2} \mathrm{~s}^{-1}$ ] illustrated that $S$. hexandrum possessed a certain shade tolerance and the presence of high $\mathrm{L}_{\mathrm{SP}}$ [approximately $1,000 \mu \mathrm{mol}\left(\right.$ photon) $\mathrm{m}^{-2} \mathrm{~s}^{-1}$ ] in herbs (Albrecht and McCarthy 2009).

During diurnal variations, $P_{\mathrm{N}}$ and $E$ under $\mathrm{ML}$ maintained higher values than those under LL and HL (Figs. 4A,C), with $g_{\mathrm{s}}$ reduced from 11:00 to 20:00 $\mathrm{h}$. These results demonstrated that $\mathrm{ML}$ was suitable for carbon assimilation and solar energy utilization (Mozzo et al. 2008). Furthermore, much water evaporation from leaf epidermis increased the heat dissipation to maintain the stability of blade temperature (Long et al. 1994, Müller et al. 2001, Baker 2008). Plant reduced $g_{\text {s }}$ and $E$ to avoid water loss during the high irradiance period (La Rocca et al. 2015), whilst the activated photosynthetic enzymes could generate the increasing of $P_{\mathrm{N}}$ quickly (Zhang et al. 2000). Therefore, the change trends of $P_{\mathrm{N}}$ and $g_{\mathrm{s}}$ were nearly synchronous under HL during the diurnal variations (Figs. 4A,B). Simultaneously, the special shade-tolerant property of $S$. hexandrum could keep the high ability of carbon assimilation in mesophyll cell under ML and LL (Fini et al. 2010), but $g_{\text {s }}$ decreased during the midday period (Figs. $4 A, B$ ). Therefore, the main determinant of $S$. hexandrum photosynthesis should be a nonstomatal factor (Jifon et al. 2003). In general, $g_{\mathrm{s}}$ was not the main regulator for $P_{\mathrm{N}}$ because $g_{\mathrm{s}}$ and $P_{\mathrm{N}}$ were insignificantly correlated $(\mathrm{r}=0.244, p>0.5)$. Shade in LL and ML significantly delayed the times of $P_{\mathrm{N}}$ peak emergence compared to that under HL, which significantly promoted the increase in $g_{\mathrm{s}}$ (Fig. $4 B$ ). These results could occur due to the high $\mathrm{S}_{\mathrm{d}}$ under shaded conditions (Table 2). Although LL or HL was unfavourable for plant growth, due to low $E$ and $W_{U E}$, such light conditions could enable the plants to adopt the corresponding strategies for survival (Valladares and Niinemets 2008).

In general, the main environmental factors significantly influenced SLM, $\mathrm{S}_{\mathrm{s}}$, and the photosynthetic characteristics of $S$. hexandrum. Several significant correlations were also observed between PAR and $P_{\mathrm{N}}, \mathrm{SLM}$ and $\mathrm{S}_{\mathrm{s}}$, which indicated that a certain PAR value was beneficial for photosynthesis, mesophyll cell (SLM), and stomatal development (Sawhney and Zelitch 1969, Lawson et al. 2014). $\mathrm{T}_{\text {air }}$ was significantly positively correlated with $P_{\mathrm{N}}$, which might be due to the cold plateau climate (Davison 1991). Moreover, a change in $\mathrm{T}_{\text {air }}$ from 16.0 to $23.4^{\circ} \mathrm{C}$ was observed during diurnal variation 
(Fig. 2). VPD air positively affected $P_{\mathrm{N}}$. According to atmospheric properties, high VPD $\mathrm{Dir}_{\text {air }}$ presented the relatively dry air, which enhanced the gas-exchange capacity through the stomata. The same results were reported by Rawson et al. (1977) and Suzuki et al. (2015).

In conclusion, our results showed that the ML regime was the best habitat for the endangered $S$. hexandrum based on the leaf traits and photosynthetic performance, such as the highest values of LA, SLM, Chl, and $\mathrm{S}_{\mathrm{s}}$, and the most active metabolism, such as $P_{\mathrm{Nmax}}, E$, and $R_{\mathrm{D}}$. Therefore, appropriate measures should be taken to promote the propagation and recovery of wild populations in the future. Firstly, the suitable habitats of $S$. hexandrum populations, such as shrubbery, and large-scale gaps, are the key protection areas, and the approach of in situ conservation is feasible. Some measures, including excessive overexploitation and collecting seeds, should be strictly forbidden. Secondly, some habitats with poor light transmittance can be partly cleared of trees and shrubs to improve light regimes and atmospheric conditions. Thirdly, the cultivated $S$. hexandrum should be supported energetically and popularised to supply/meet the market demand.

\section{References}

Aasamaa K., Sõber A.: Stomatal sensitivities to changes in leaf water potential, air humidity, $\mathrm{CO}_{2}$ concentration and light intensity, and the effect of abscisic acid on the sensitivities in six temperate deciduous tree species. - Environ. Exp. Bot. 71: 72-78, 2011.

Albrecht M.A., McCarthy B.C.: Seedling establishment shapes the distribution of shade-adapted forest herbs across a topographical moisture gradient. - J. Ecol. 97: 1037-1049, 2009.

Baker N.R.: Chlorophyll fluorescence: a probe of photosynthesis in vivo. - Annu. Rev. Plant Biol. 59: 89-113, 2008.

Camargo M.A.B., Marenco R.A.: Density, size and distribution of stomata in 35 rainforest tree species in Central Amazonia. - Acta Amazon. 41: 205-2012, 2011.

Campos M.L., Yoshida Y., Major I.T. et al:: Rewiring of jasmonate and phytochrome B signalling uncouples plant growth-defense tradeoffs. - Nat. Commun. 7: 12570, 2016.

Chapin F.S., Bloom A.J., Field C.B. et al.: Plant responses to multiple environmental factors. - Bioscience 37: 49-57, 1987.

Davison I.R.: Environmental effects on algal photosynthesis: temperature. - J. Phycol. 27: 2-8,1991.

Duanmu D., Casero D., Dent R.M. et al.: Retrograde bilin signaling enables Chlamydomonas greening and phototrophic survival. - P. Natl. Acad. Sci. USA 110: 3621-3626, 2013.

Farquhar G.D, Sharkey T.D.: Stomatal conductance and photosynthesis. - Annu. Rev. Plant Physio. 33: 317-345, 1982.

Fini A., Ferrini F., Frangi P. et al.: Growth, leaf gas exchange and leaf anatomy of three ornamental shrubs grown under different light intensities. - Eur. J. Hortic. Sci. 75: 111-117, 2010.

Fu L., Chin C.M.: [China Plant Red Data Book.] Pp. 87. Science Press, Beijing 1992. [In Chinese]

Galloway L.F., Etterson J.R.: Plasticity to canopy shade in a monocarpic herb: within-and between-generation effects. New Phytol. 182: 1003-1012, 2009.

Givnish T.J.: Adaptation to sun and shade: a whole-plant perspective. - Funct. Plant Biol. 15: 63-92, 1988.
Gregoriou K., Pontikis K., Vemmos S.: Effects of reduced irradiance on leaf morphology, photosynthetic capacity, and fruit yield in olive (Olea europaea L.). - Photosynthetica 45: 172-181, 2007.

Guo Q.Q., Li H.E., Zhang W.H.: Variations in leaf functional traits and physiological characteristics of Abies georgei var. smithii along the altitude gradient in the Southeastern Tibetan Plateau. - J. Mt. Sci. 13: 1818-1828, 2016.

Guo Q.Q., Wang S.L., Ren D.Z. et al.: [Environment factors and characteristics of endangered Sinopodophyllum hexandrum communities in Tibet.] - J. Lanzhou Univ. 48: 58-63, 2012. [In Chinese]

Huber H., Brouwer J.D., Caluwe H.D. et al:: Shade induced changes in biomechanical petiole properties in the stoloniferous herb Trifolium repens. - Evol. Ecol. 22: 417 417, 2008.

Jifon J.L., Syvertsen J.P.: Moderate shade can increase net gas exchange and reduce photoinhibition in citrus leaves. -Tree Physiol. 23: 119-127, 2003.

Kenzo T., Yoneda R., Sano M. et al.: Variations in leaf photosynthetic and morphological traits with tree height in various tree species in a Cambodian tropical dry evergreen forest. - JARQ-Jpn. Agr. Res. Q. 46: 167-180, 2012.

Kumari A., Singh H.R., Jha A. et al.: Transcriptome sequencing of rhizome tissue of Sinopodophyllum hexandrum at two temperatures. - BMC Genom. 15: 1-17, 2014.

La Rocca N., Sciuto K., Meneghesso A. et al.: Photosynthesis in extreme environments: responses to different light regimes in the Antarctic alga Koliella antarctica. - Physiol. Plantarum 153: 654-667, 2015.

Lawson T., Davey P.A., Yates S.A. et al.: $\mathrm{C}_{3}$ photosynthesis in the desert plant Rhazya stricta is fully functional at high temperatures and light intensities. - New Phytol. 201: 862873,2014

LiZ.Z.,Liu D.H.,Zhao S.W.etal:: [Mechanisms of photoinhibition induced by high light in Hosta grown outdoors.] - Chin. J. Plant Ecol. 38: 720-728, 2014. [In Chinese]

Liu W., Liu J., Yin D. et al:: Influence of ecological factors on the production of active substances in the anti-cancer plant Sinopodophyllum hexandrum (Royle) TS Ying. - PLoS ONE 10: e0122981, 2015.

Long S.P., Humphries S., Falkowski P.G.: Photoinhibition of photosynthesis in nature. - Annu. Rev. Plant Biol. 45: 633662,1994

Lu J., Lan X, Luo J.: [Investigation and evaluation of the rare and endangered Tibetan medicinal plants in the Linzhi Region.] Resour. Sci. 33: 2362-2369, 2011. [In Chinese]

Ma S.B., Hu, Z.H.: [Preliminary studies on the distribution pattern and ecological adaptation of Sinopodophyllum hexandrum (Royal) Ying (Berberidaceae).] - J. Wuhan Bot. Res. 14: 47-54, 1996. [In Chinese]

Ma S.B., Xu Z.R., Hu, Z.H.: [Acontribution to the reproductive biology of Sinopodophyllum hexandrum (Royal) Ying (Berberidaceae).] - Acta Bot. Boreal. Occident. Sin. 17: 4955, 1997. [In Chinese]

Magyar G., Kun A., Oborny B. et al.: Importance of plasticity and decision-making strategies for plant resource acquisition in spatio-temporally variable environments. - New Phytol. 174: 182-193, 2007.

Meinzer F.C., Grantz D.A.: Stomatal and hydraulic conductance in growing sugarcane: stomatal adjustment to water transport capacity. - Plant Cell Environ. 13: 383-388, 1990.

Mozzo M., Passarini F., Bassi R. et al:: Photoprotection in higher plants: the putative quenching site is conserved in all outer light-harvesting complexes of photosystem II. - BBABioenergetics 1777: 1263-1267, 2008. 
Müller P., Li X.P., Niyogi K.K.: Non-photochemical quenching. A response to excess light energy. - Plant Physiol. 125: 1558$1566,2001$.

Nadeem A., Kashani S., Ahmed N. et al.: Growth and yield of sesame (Sesamum indicum L.) under the influence of planting geometry and irrigation regimes. - Am. J. Plant Sci. 6: 980986, 2015.

Ou Z.Y., Cao J.Z., Shen W.H. et al.: Understory flora in relation to canopy structure, soil nutrients, and gap light regime: a case study in southern China. - Pol. J. Environ. Stud. 24: 25592568, 2015.

Petter G., Wagner K., Wanek W. et al.: Functional leaf traits of vascular epiphytes: vertical trends within the forest, intra- and interspecific trait variability, and taxonomic signals. - Funct. Ecol. 30: 188-198, 2016.

Pigliucci M., Kolodynska A.: Phenotypic plasticity to light intensity in Arabidopsis thaliana: invariance of reaction norms and phenotypic integration. - Evol. Ecol. 16: 27-47, 2002.

Pilahome W., Bunnag S., Suwanagul A.: Two-step salt stress acclimatization confers marked salt tolerance improvement in four rice genotypes differing in salt tolerance. - Arab. J. Sci. Eng. 42: 2191-2200, 2017.

Pons T.L.: Regulation of leaf traits in canopy gradients. - In: Kouki H., Ülo N., Niels P.R.A. (ed.):Canopy Photosynthesis: From Basics to Applications. Pp. 143-168. Springer, Dordrecht 2016.

Portsmuth A., Niinemets Ü.: Structural and physiological plasticity in response to light and nutrients in five temperate deciduous woody species of contrasting shade tolerance. Funct. Ecol. 21: 61-77, 2007.

Puglielli G., Varone L., Gratani L. et al.: Specific leaf area variations drive acclimation of Cistus salvifolius in different light environments. - Photosynthetica 55: 31-40, 2017.

Rawson H.M., Begg J.E., Woodward R.G.: The effect of atmospheric humidity on photosynthesis, transpiration and water use efficiency of leaves of several plant species. Planta 134: 5-10, 1977.

Rodríguez-López N.F., Martins S.C., Cavatte P.C. et al.: Morphological and physiological acclimations of coffee seedlings to growth over a range of fixed or changing light supplies. - Environ. Exp. Bot. 102: 1-10, 2014.

Santiago L.S., Wright S.J.: Leaf functional traits of tropical forest plants in relation to growth form. - Funct. Ecol. 21: 19-27, 2007.

Sato R., Ito H., Tanaka A.: Chlorophyll $b$ degradation by chlorophyll $b$ reductase under high-light conditions. Photosynth. Res. 126: 249-259, 2015.

Sawhney B.L., Zelitch I.: Direct determination of potassium ion accumulation in guard cells in relation to stomatal opening in light. - Plant Physiol. 44: 1350-1354, 1969.

Suzuki M., Umeda H., Matsuo S. et al.: Effects of relative humidity and nutrient supply on growth and nutrient uptake in greenhouse tomato production. - Sci. Hortic.-Amsterdam 187: 44-49, 2015.

Terashima I., Miyazawa S.I., Hanba Y.T.: Why are sun leaves thicker than shade leaves? - Consideration based on analyses of $\mathrm{CO}_{2}$ diffusion in the leaf. - J. Plant Res. 114: 93-105, 2001.

Thornley J.H.M.: Mathematical Models in Plant Physiology. Pp. 85-106. Academic press, London 1976.

Tomlinson P.B.: The Structural Biology of Palms. Clarendon Press, Oxford 1990.

Tucci M.L.S., Erismann N.M., Machado E.C. et al.: Diurnal and seasonal variation in photosynthesis of peach palms grown under subtropical conditions. - Photosynthetica 48: 421-429, 2010.

Uddling J., Gelang-Alfredsson J., Piikki K. et al.: Evaluating the relationship between leaf chlorophyll concentration and SPAD-502 chlorophyll meter readings. - Photosynth. Res. 91 : 37-46, 2007.

Valladares F., Niinemets Ü.: Shade tolerance, a key plant feature of complex nature and consequences. - Annu. Rev. Ecol. Evol. S. 39: 237-257, 2008.

Xiao H., Wang C., Liu J. et al.: Insights into the differences in leaf functional traits of heterophyllous Syringa oblata under different light intensities. - J. Forestry Res. 26: 613-621, 2015.

Xiao M., Li Q., Guo L. et al.: AFLP analysis of genetic diversity of the endangered species Sinopodophyllum hexandrum in the Tibetan region of Sichuan Province, China. - Biochem. Genet. 44: 44-60, 2006.

Yannelli F.A., Koch C., Jeschke J.M. et al.: Limiting similarity and darwin's naturalization hypothesis: understanding the drivers of biotic resistance against invasive plant species. Oecologia 183: 775-784, 2017.

Zhao L., Yang Y., Lin D.: Effects of light intensity on photosynthetic characteristics and quality of Taraxacum mongolicum. - Acta Horti. Sin. 34: 1555-1558, 2007.

Zhang S., Gao R.: Diurnal changes of gas exchange, chlorophyll fluorescence, and stomatal aperture of hybrid poplar clones subjected to midday light stress. - Photosynthetica 37: 559571,2000

(C) The authors. This is an open access article distributed under the terms of the Creative Commons BY-NC-ND Licence. 